\title{
Thermo-mechanical Investigation of Ventilated Disc Brake with Finite Element Analysis
}

\author{
Arifin $^{\# 1}$, Mohammad Tauviqirrahman ${ }^{\# 2}$, Muchammad ${ }^{* 3}$, J. Jamari ${ }^{\#}$, A.P. Bayuseno ${ }^{\#}$ \\ \# Laboratory for Engineering Design and Tribology, \\ Mechanical Engineering Department, Diponegoro University \\ Jl. Prof. Soedharto, Tembalang, Semarang, Indonesia, Phone: 024-7460059 \\ ${ }^{1}$ arifinypt97@gmail.com \\ ${ }^{2}$ mohammad.tauviqirrahman@ft.undip.ac.id \\ * Laboratory for Surface Technology and Tribology, \\ Faculty of Engineering Technology, University of Twente \\ Drienerloolaan 5, Postbus 217, 7500 AE, Enschede, The Netherlands \\ 3 m_mad5373@yahoo.com
}

\begin{abstract}
Braking is a process of absorbing energy from a moving system of the vehicle. Excessive temperature during braking may affect the function of the braking system. This paper investigates the thermal characteristic (i.e. the temperature and total heat flux) as well as the structural mechanical behaviour (i.e. of total deformation and von Mises stress) of the ventilated disc brake during single brake with the finite element analysis, aiming to help designers obtain appropriate design parameters. A system coupling analysis between thermal and mechanical approach is performed to get comprehensive results. The number of ventilation holes is varied. The simulation results show that the number of the holes of the disc is an essential factor in the improvement of cooling process of the disc. It is confirmed that the large number of ventilation holes gives a positive effect on the thermal and mechanical characteristic of the disc. The obtained results by this simulation can be considered as a guideline to the optimal ventilated disc design.
\end{abstract}

Keyword - Brake disc, Finite element analysis, Temperature, Ventilated disc

\section{INTRODUCTION}

As is well known, the brake system as a part of the automobile safety system has a significant role in protecting the passengers and driver. Disc brake systems are widely used in light vehicles. However, one main problem of the use of disc brakes is temperature rise due to long repetitive braking. The increase in the temperature during braking leads to the decrease in the performance of the brake system. In detail, high temperature of disc brake may cause premature wear, bearing failure and thermal crake [1]. Therefore, it is necessary to assess the temperature rise of a given disc brake for achieving the best performance of braking system.

In order to cool the disc brake, ventilated brake disc have been widely applied. Such disc can sandwich heat dissipation elements. For improving the cooling performance of the ventilated disc brake, considerable efforts have been performed by researchers. Yan et al. [2] proposed a design of X-type lattice cored ventilated brake disc. Experimentally and numerically, detailed thermo-fluidic characteristics of this new brake disc were investigated. They concluded that heat transfer on core surface is substantially improved, which acts as the dominant mechanism for enhanced overall cooling performance of the new brake disc. Vivek and Chopra [3] using a finite element analysis compared the performance of the ventilated disc brake with the solid disc brake with respect to the thermal characteristics combining the thermal and structural analysis. The variation of the material used was also carried out. In order to enhance the braking efficiency and provide greater stability to the vehicle, an investigation of the comparison analysis between the solid disc brake and ventilated disc brake was also carried out by Narayana et al. [4] focusing the usage of materials. The temperature distribution, variation of the stresses and deformation across the disc brake profile either in solid disc or ventilated disc were also investigated. It was found that ventilated type disc brake is the best possible for the present application of disc brake system compared to the solid disc brake. In addition, they suggested that glass fiber is the best material for disc brake. The other interesting study was published by Kiran [5] who investigated the cooling effect of the ventilated disc on the temperature characteristic using the interaction of CFD (computational fluid dynamic) and thermal analysis. The author used a complete 3D model of car for the computational domain. From this, the loading could be more realistic to predict the braking system. Several designs of the rotor of the braking system were proposed and compared each other regarding to the adequate cooling. Hwang and Wu [6] using multi-body model technique investigated the temperature and thermal stress in the ventilated disc-pad brake during single 
brake. The brake disc was decelerated at the initial speed with constant acceleration, until the disc comes to a stop. The main outcome of the study was that the temperature field affects the thermal expansion and leads to variation of contact pressure distribution. They found that lower temperature in the vanes was due to the effect of disc conductivity and higher convection in the vanes.

Later, following works focusing on thermal effect on the performance of brake system were dedicated by Belhocine and Bouchetara [7]-[10]. They showed that the von Mises stress and the total deformations of the disc and contact pressures of the brake pads increase in a significant way when the thermal and mechanical aspects were coupled [7]. Identification of the factors and the entering parameters concerned at the time of the braking operation, such as the type of braking, the geometric design of the disc and the material were also investigated [8]. In addition, it was found that the radial ventilation plays a very significant role in cooling of the disc in the braking phase [9].

While considering this scientific context, the main aim of this work is to study the temperature profile of disc brake induced by the ventilation effect using a finite element analysis. In addition, the structural mechanical characteristic of the disc is also investigated using a coupling analysis between the thermal and structural mechanical approach. In order to achieve this, several cases are considered regarding with the number of the ventilation holes. Minimizing the temperature that affects the braking performance is of particular interest.

\section{NUMERICAL MODELLING AND ITS SOLUTION}

In order to investigate the effect of the ventilation of on the thermo mechanical performance of the disc brake, computations have been made by varying the number of the ventilation holes. To get results, first, it is intended to validate the numerical code based on finite element method (FEM) which is developed in FEM based commercial software ANSYS. The comparison between the full disc and ventilated disc is of main interest regarding to the validation step. Finally, the effect of the number of the ventilation holes on the thermal and structural mechanical characteristics of the disc brake is explored.

From the numerical point of view, for solving the problems, there are several numerical steps that must be performed. The first step is to create the three-dimensional geometry model which contains the fields to be studied in ANSYS Workbench. Two kinds of disc brake are considered, i.e. full disc brake and ventilated disc brake. In this research, for investigating the performance of the ventilated disc brake, the number of the ventilation holes are varied. The number of holes of 24, 30, 36, 42 and 48 are of particular interest. The second step is to conduct an analysis of thermal of the disc using a steady state thermal analysis provided by ANSYS. From the simulation, the thermal stress can be retrieved. The final step is to perform the mechanical analysis using the steady state structural analysis with the surface temperature as the input of the boundary condition. From this, more comprehensive result of the disc simulation can be found.

Table I represents the material properties of the disc used in the present study. In the present study, the cast iron is used for the disc material. In all following computations, the boundary condition is set as follows:

- A heat transfer by convection on all free surfaces of the disc.

- A heat flux entering the disc.

TABLE I. Material properties used in the simulation

\begin{tabular}{|l|c|c|}
\hline Thermal conductivity & $\mathrm{k}(\mathrm{W} / \mathrm{mK})$ & 54 \\
\hline Density & $\rho\left(\mathrm{kg} / \mathrm{m}^{3}\right)$ & 7,100 \\
\hline Specific heat & $c(\mathrm{~J} / \mathrm{KgK})$ & 586 \\
\hline Poisson's ratio & $v$ & 0.25 \\
\hline Coefficient of thermal expansion & $\alpha\left(10^{-6} / \mathrm{K}\right)$ & $9.9 \times 10^{-6}$ \\
\hline Young modulus & $E(\mathrm{GPa})$ & 125 \\
\hline
\end{tabular}

III. RESULTS AND DISCUSSIONS

\section{A. Validation of solution method}

In the present study, to ensure the validity of the numerical method developed here and thus the accurate solution, it is necessary to investigate special case. Generating the mesh density as well as its configuration and handling the element reliably and giving the suitable boundary conditions are quite important steps in the analysis of thermo-mechanical conducted here. For achieving this, the work of Narayana et al. [4] is considered as benchmark. The full disc brake made of cast iron is of particular interest and is shown in Fig. 1(a). The material properties for such disc are shown in Table I. 
In this simulation, the meshing is carried using an automatic mesh feature due to simplicity. Figure 1(b) depicts the meshed model with 24,607 nodes and 13,880 elements based on the result of the independent mesh study.

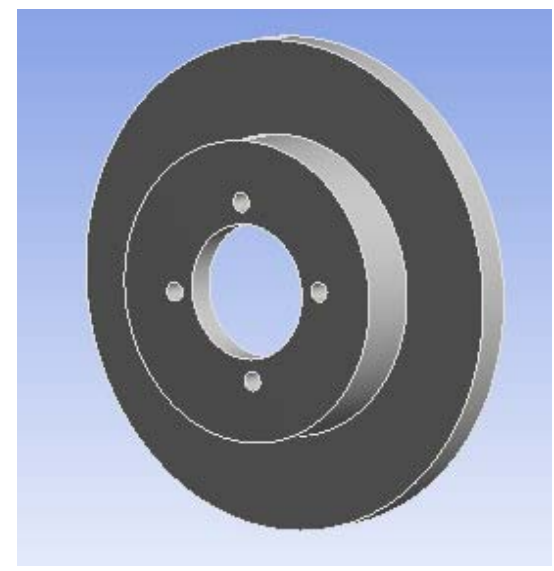

(a)

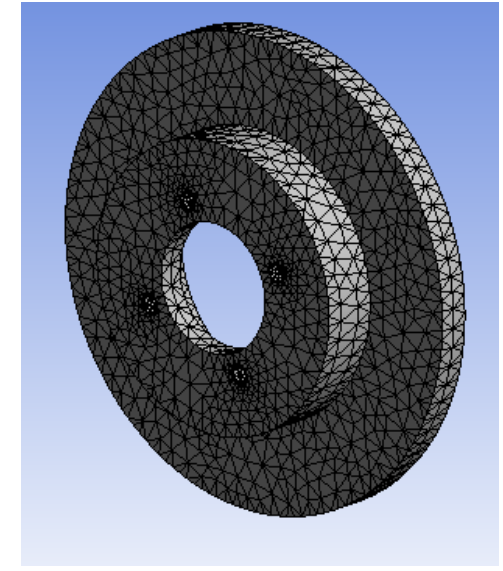

(b)

Fig. 1. (a) 3D geometry model of full disc brake, (b) meshing of a full disc in ANSYS (24,607 nodes - 13,880 elements)

Table II shows the comparison result between the present study and the published work [4]. Based on Table II, it is confirmed that that for cast iron disc, the predicted of the total heat flux profile is in a good agreement with published work [4]. The simulation shows that the maximum total heat flux is $29,636 \mathrm{~W} / \mathrm{m}^{2}$ which means that there is no deviation compared to the literature. The distribution of the total heat flux predicted by the present simulation is depicted in Figure 2. In general, it can be concluded that the numerical code containing the boundary condition developed here is valid. Therefore, using this code as well as the algorithm, the research can be extended to the case of the ventilated disc brake due to their advantages over the full solid disc as mentioned in the previous section.

TABLE II. Validation result

\begin{tabular}{|l|c|c|c|}
\hline \multirow{2}{*}{} & \multicolumn{3}{|c|}{ Maximum total heat flux (W/m² } \\
\cline { 2 - 4 } & Published work [4] & Present study & Error (\%) \\
\hline Cast iron full disc & 29,636 & 29,636 & 0 \\
\hline
\end{tabular}

A: Steady-State Thermal
Total Heat Flux
Type: Total Heat Flux
Unit: W/m²
Time: 1
\begin{tabular}{|l}
29636 Max \\
26344 \\
23052 \\
19760 \\
16468 \\
13176 \\
9884 \\
6592 \\
3300 \\
8.0603 Min
\end{tabular}

Fig. 2. Contour of total heat flux for full disc predicted by the present simulation

\section{B. Effect of number of ventilation holes}

As mentioned in the previous section, a coupling analysis between the thermal and mechanical analysis is used in the simulation. The thermal analysis leads to the prediction of the temperature and total heat flux distribution of the ventilated disc, while the mechanical analysis gives the structural characteristic which describes the stress and the deformation of the disc. For all following computations, the cast iron is used as disc material. The holes of 24, 30, 36, 42, and 48 are compared with respect to the thermo-mechanical characteristic. For schematic representation, Figure 3 shows the geometry model of ventilated discs with 24 and 48 holes, respectively, while Figure 4 depicts the meshed model. 


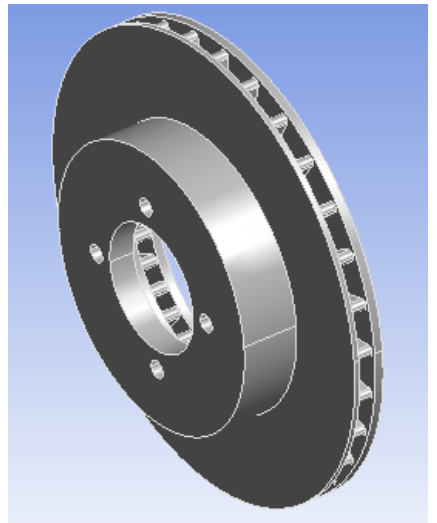

(a)

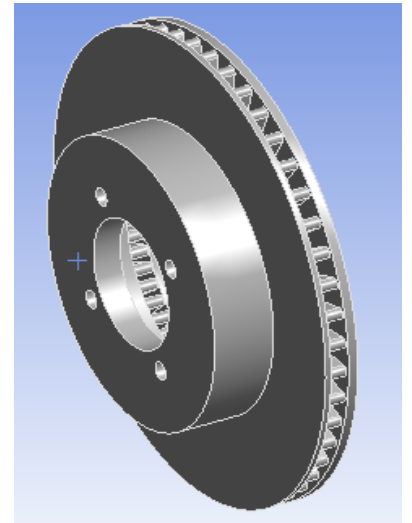

(b)

Fig. 3. The ventilated disc geometry with (a) 24 holes, and (b) 48 holes in isometric view

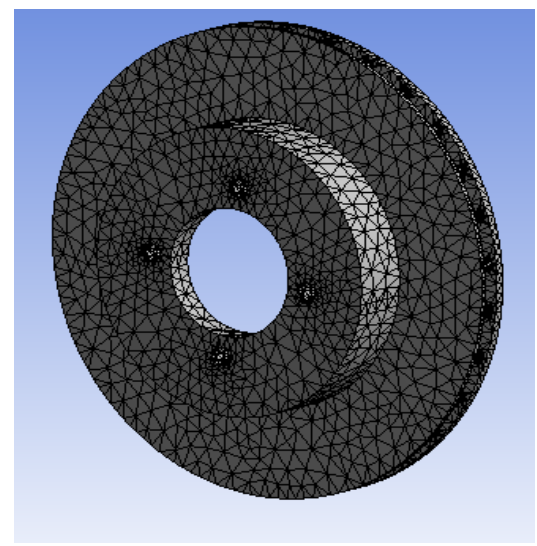

(a)

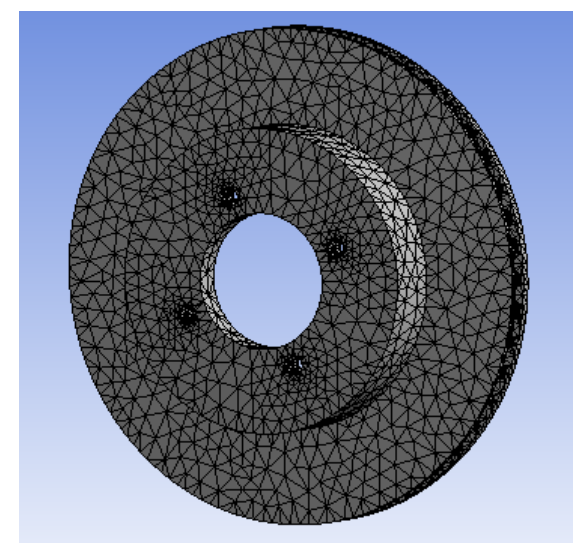

(b)

Fig. 4. The mesh of ventilated disc with (a) 24 holes, and (b) 48 holes in isometric view

Figures 5-8 show the simulation results of the ventilated disc varying the number of the ventilation hole with respect to thermal characteristic (i.e. the temperature and the total heat flux profile) and the structure characteristic (i.e. the deformation and the von Mises stress distribution). It can be shown based on Fig. 5 that with respect to the temperature distribution, the larger the number of ventilation holes, the lower the maximum local temperature as well as the range of the temperature distribution. It indicates that the ventilation holes have a positive effect on reducing the temperature. The most possible explanation is when the ventilated disc with large number of holes is used in brake system; the circulation of air flow tends to cool the hot disc more quickly. Based on physical point of view, the decrease in temperature range which occurs during the braking leads to the increase in the efficiency of braking. This will prevent the possibility of the change of brake fluid phase to other phase (vapour). As is known that when the liquid phase changes to the vapour phase, the so called as brake failure will occur and as consequence this will endanger the driver and the passengers.

Figure 6 depicts the total heat flux distribution for ventilated disc with different holes number values. It is found that the trend of the total heat flux distribution is similar to the trend of temperature profile. This is as expected because when temperature variation is low due to the presence of large holes number, the heat transferred from the source of the heat (i.e. the contact between the pad and the disc) tends to be low. This is because more air entering the disc through the ventilation holes makes a natural cooling to several hot spots of the disc surface. It can be seen that he maximum total heat flux is located at edge of the inner cylinder (see Figs. 6 (c) and (e) for detail). This prevails for all cases considered here. In the regions close to the outer disc (i.e. the ventilated area), the total heat flux have a minimum value. On the other words, the number of the holes of the disc is an essential factor in the improvement of cooling process of the disc.

Figure 7 reflects the variation of the total deformation versus the number of ventilation holes. It is confirmed that increasing the ventilation holes does not change the total deformation variation very much. For example, in the case of 24 ventilation holes, the maximum total deformation is 0.555 or just $25 \%$ lower than that with 48 ventilation holes. It indicates that subject to the structure characteristic, the increase in the number of the holes in the ventilated disc does not affect the stability and the strength performance of the disc. 
Figure 8 shows the von Mises stress distribution through a disc varying number of holes. It can be seen that the increase in the number of holes leads to the decrease in the range of the von Mises stress. As consequence, this positive effect will reduce the possibility of the failure of structure. If the maximum von Mises stress can be reduced due to the existence of holes, the safety factor of the ventilated disc can be increased. It is interesting to note that the optimal number of holes for the design of ventilated disc is 48, because it gives the lowest the maximum von Mises stress. Based on Fig. 8, it can be also shown that the location of the maximum von Mises stress is close to the region of holes.

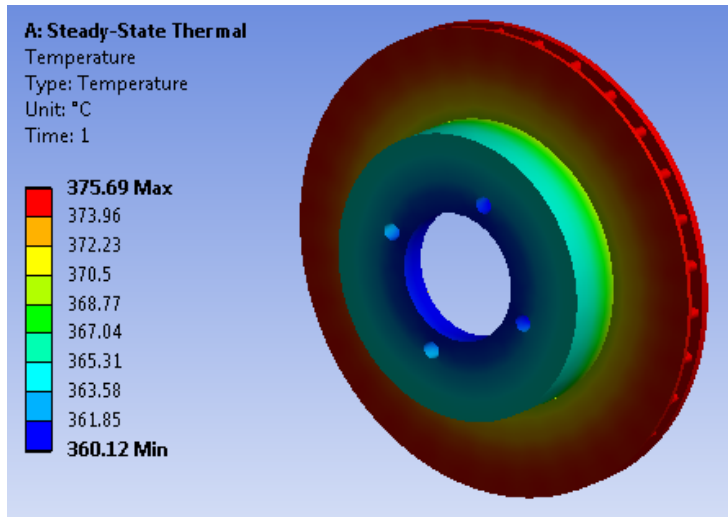

(a)

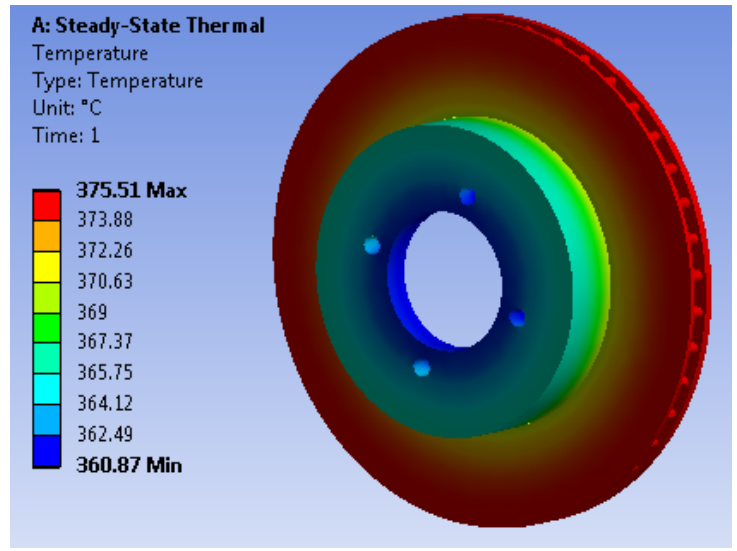

(c)

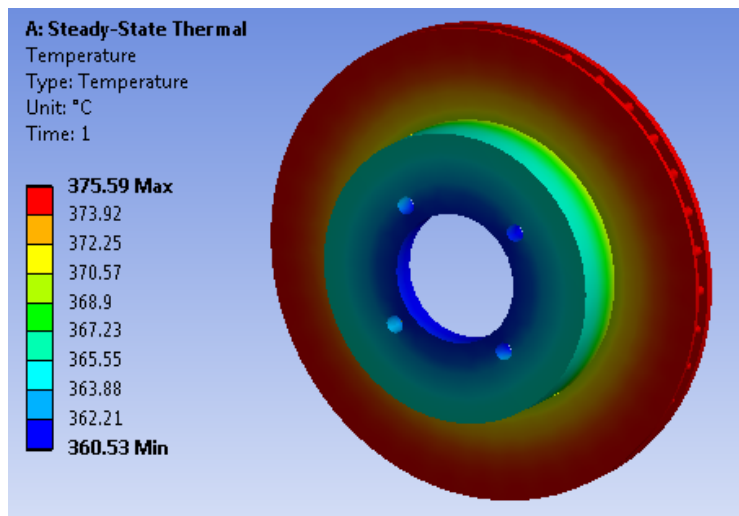

(b)

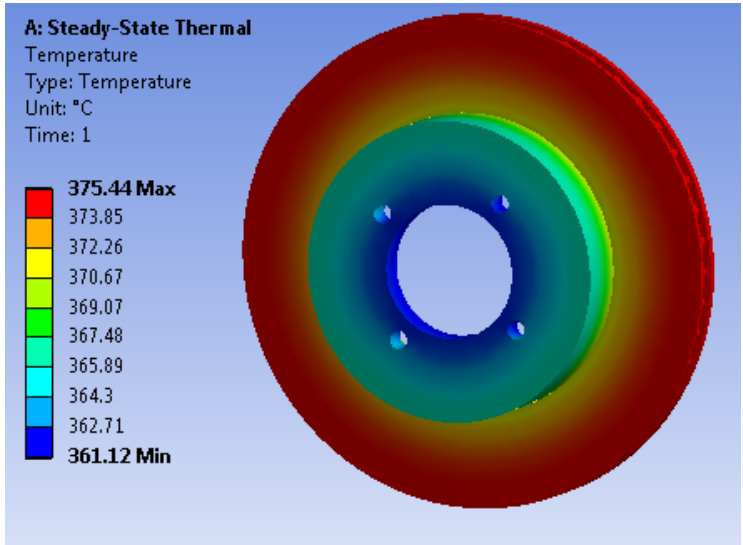

(d)

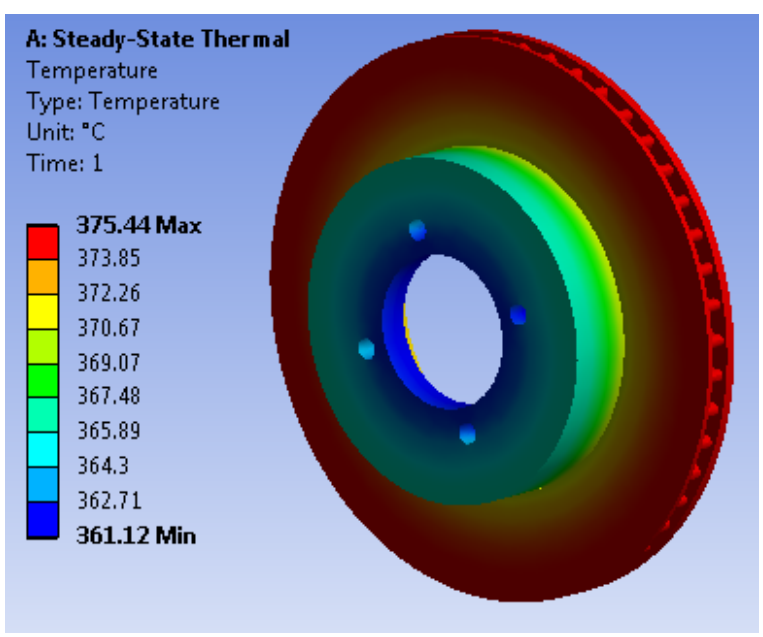

(e)

Fig. 5. Temperature variation through a ventilated disc for (a) 24, (b) 30, (c) 36, (d) 42 and (e) 48 holes. 


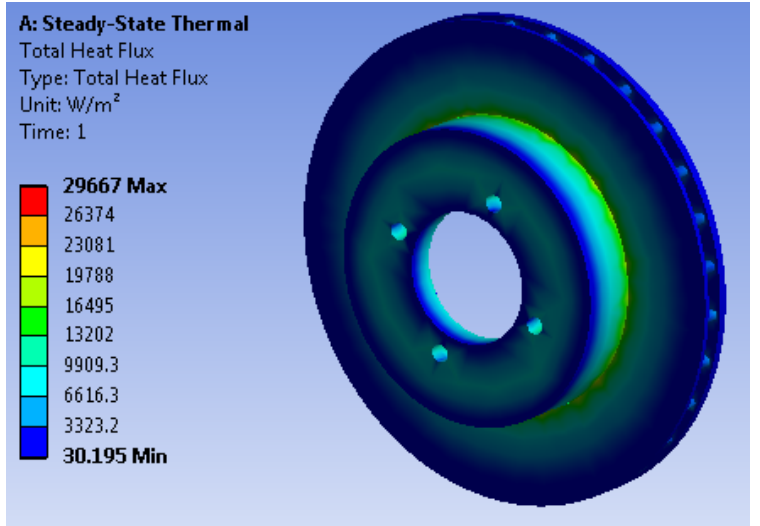

(a)

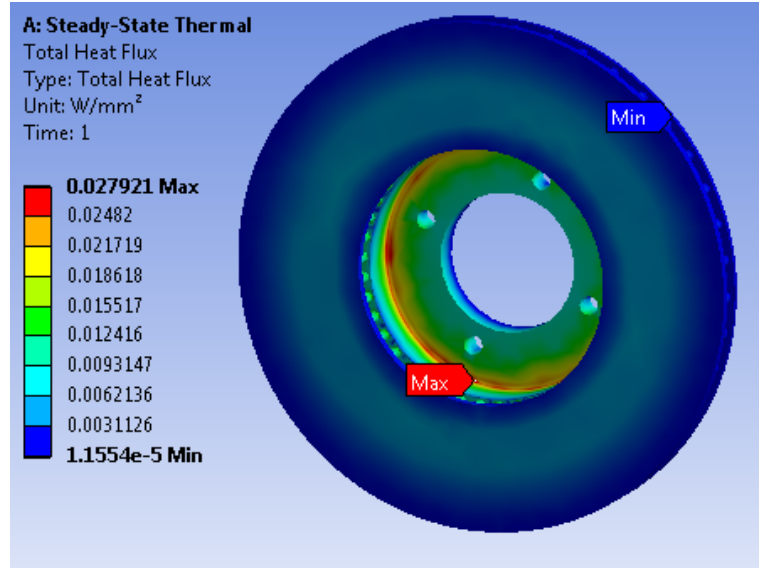

(c)

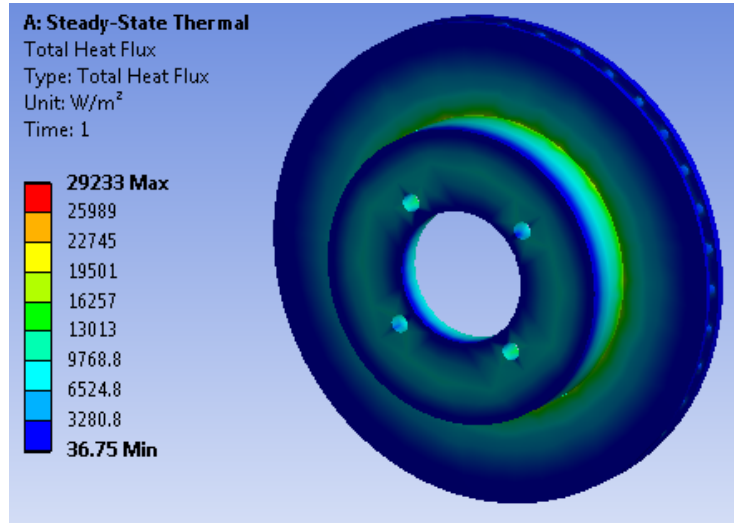

(b)

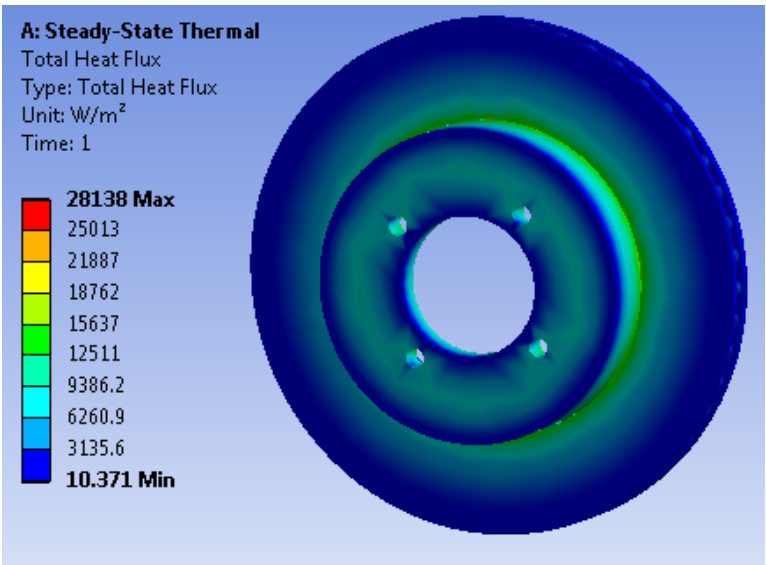

(d)

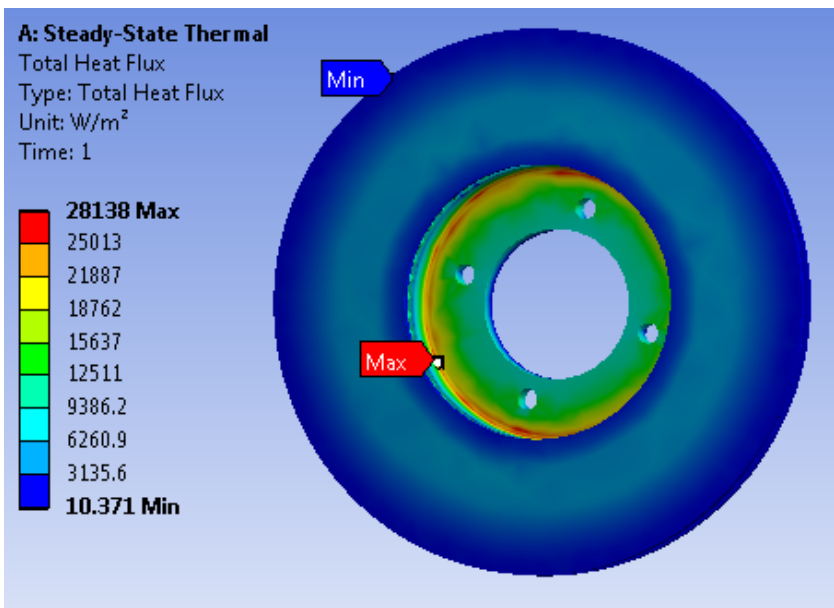

(e)

Fig. 6. Total heat flux profile through a ventilated disc for (a) 24, (b) 30, (c) 36, (d) 42 and (e) 48 holes. 


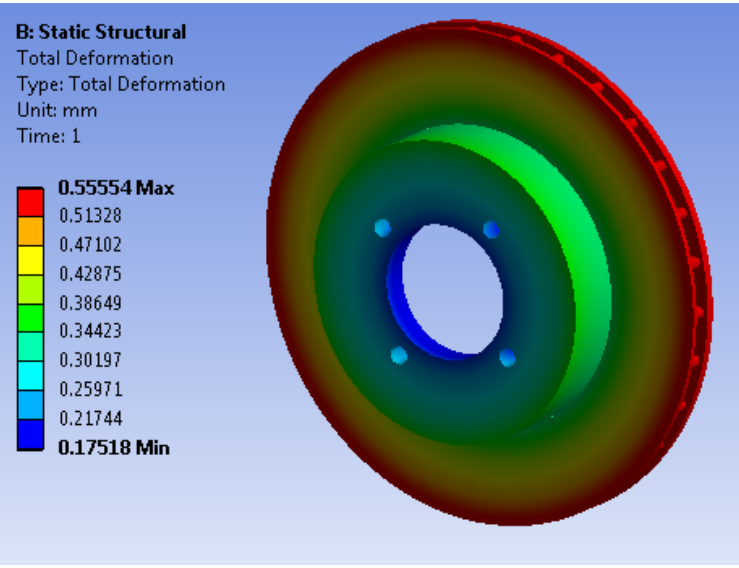

(a)

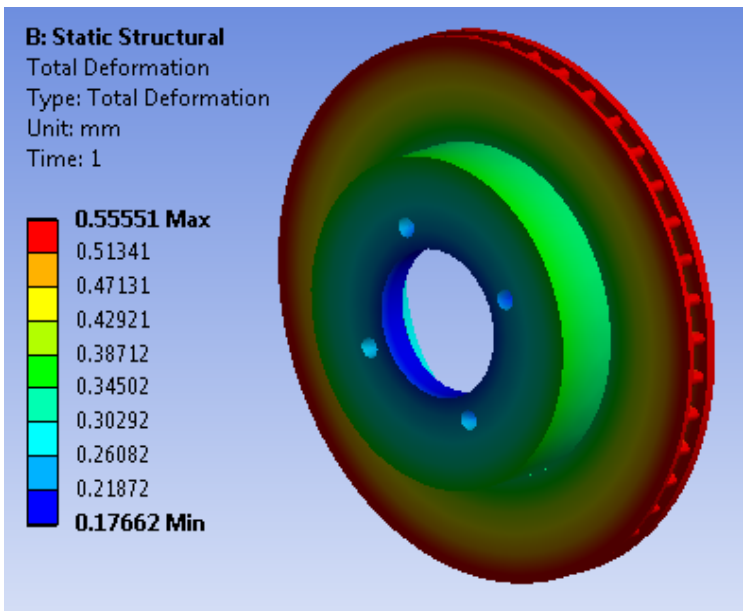

(c)

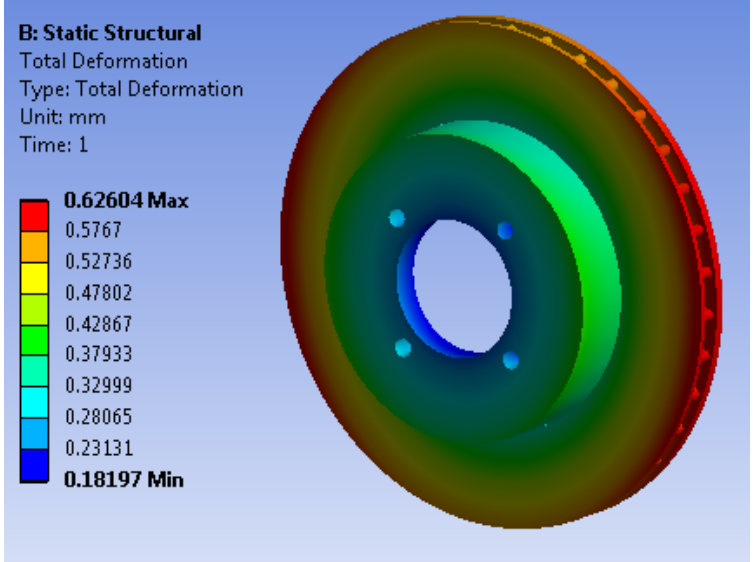

(b)

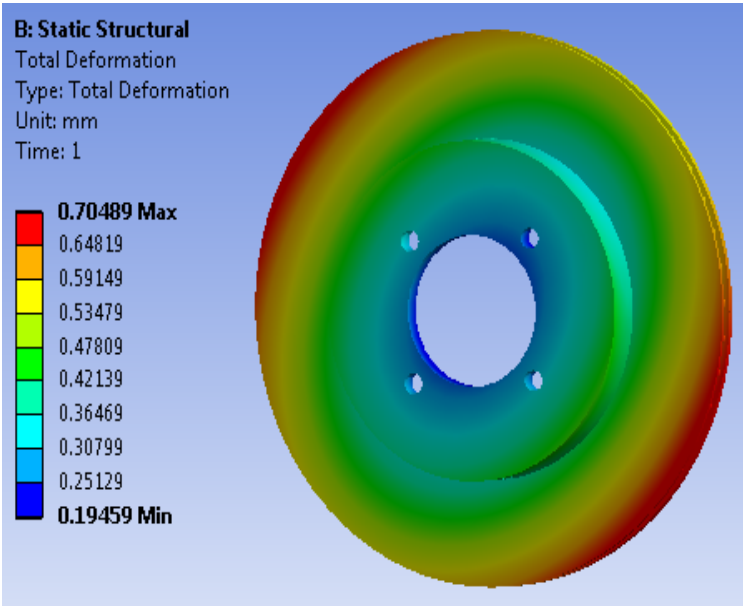

(d)

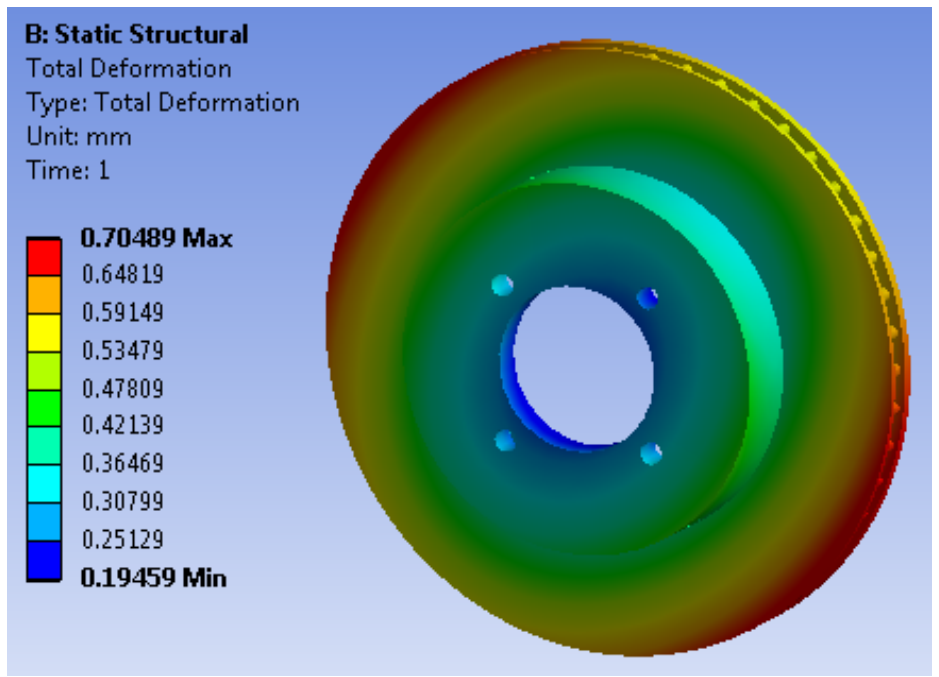

(e)

Fig. 7. Deformation distribution through a ventilated disc for (a) 24, (b) 30, (c) 36, (d) 42 and (e) 48 holes. 


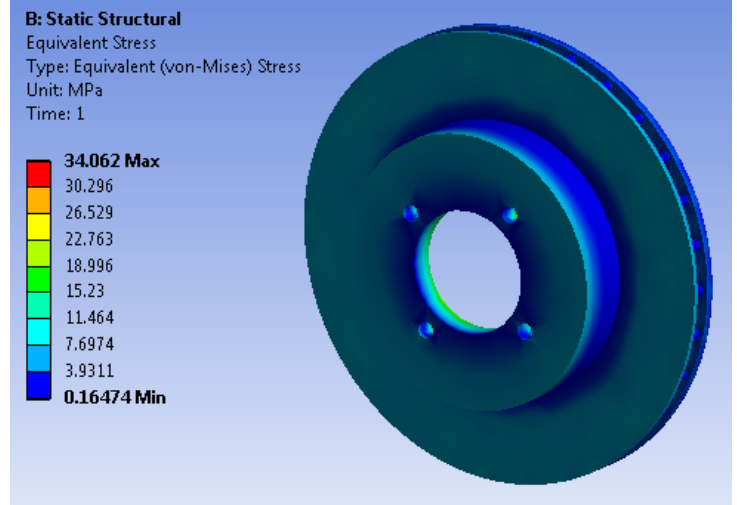

(a)

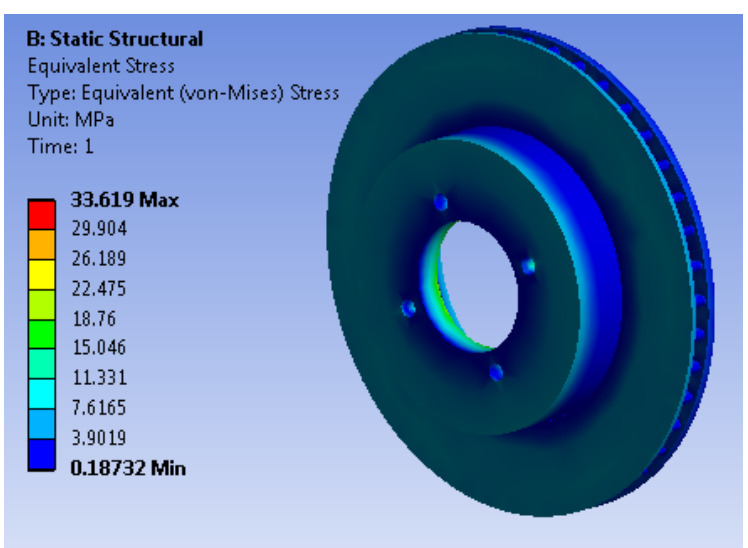

(c)

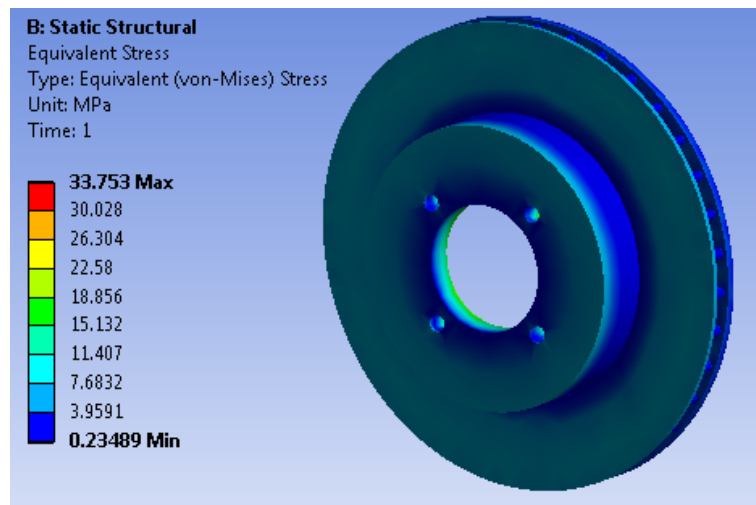

(b)

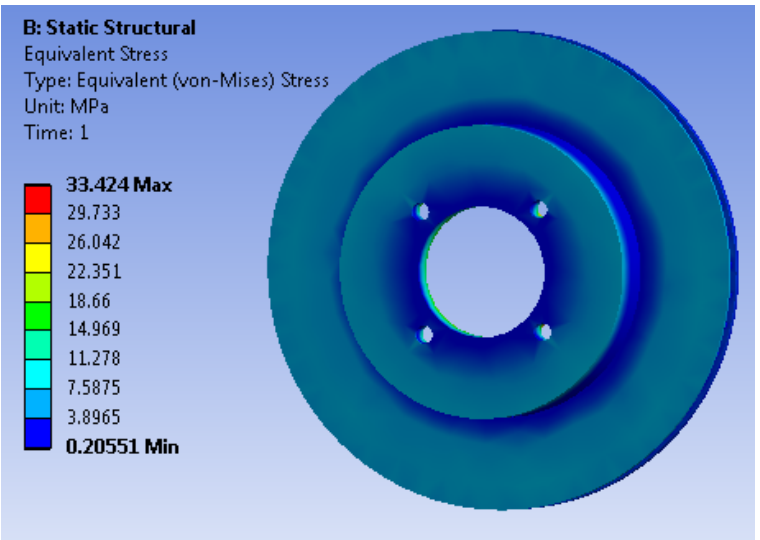

(d)

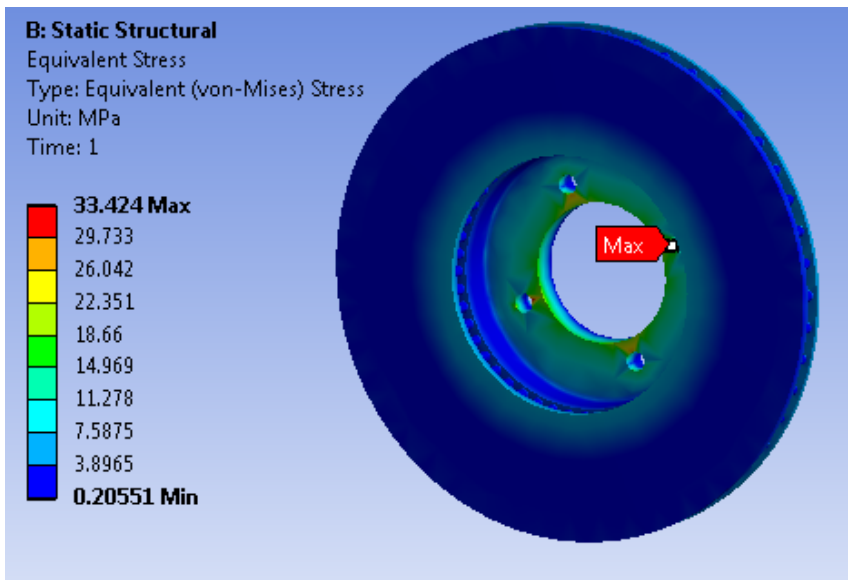

(e)

Fig. 8. Von Mises stress distribution through a ventilated disc for (a) 24, (b) 30, (c) 36, (d) 42 and (e) 48 holes.

\section{IV.CONCLUSION}

The aim of the investigation was to examine how many ventilation holes of the disc brake which may reduce the excessive temperature of the structure due to braking. A numerical simulation of the thermal behavior of a solid and ventilated disc in steady state was performed using finite element method based software ANSYS. In addition, the structural mechanical analysis was also performed using a couple analyses to get more comprehensive results. The conclusions can be summarized as follows:

1. The larger the number of the ventilation holes, the lower the maximum temperature variation.

2. Increasing the number of the ventilation holes does not change the total deformation variation very much.

3. The increase in the number of holes leads to the decrease in the range of the von Mises stress.

These findings are very useful for the study of the performance of the ventilated disc brake with respect to the temperature rise during the braking. 


\section{REFERENCES}

[1] S. J. F. Talati, "Investigation of heat transfer phenomena in a ventilated disk brake rotor with straight radial rounded vanes,” J. Appl. Sci., vol. 8, no. 20, pp. 3583-3592, 2008.

[2] H. B. Yan, Q. C. Zhang, and T. J. Lu, “Heat transfer enhancement by X-type lattice in ventilated brake disc,” Int. J. Therm. Sci., vol. 107, pp. 39-55, 2016.

[3] Vivek Agnihotri \& M.K. Chopra, “Optimized thermo-structural analysis of solid and vented disc brake using finite element method (A case study),” IOSR J. Mech. Civ. Eng., vol. 11, no. 4, pp. 40-49, 2014.

[4] K. S. Narayana, G. U. Rao, D. Simhachalam, and B. Nagaraju, "Finite element analysis of solid and ventilated disc brake," Int. J. Sci. Res., vol. 3, no. 9, pp. 875-882, 2014.

[5] C. H. Kiran, “Numerical simulation of ventilated disc cooling effect,” Int. J. Mech. Eng. Robot. Res., vol. 4, no. 1, pp. $257-270,2015$.

[6] P. Hwang and X. Wu, "Investigation of temperature and thermal stress in ventilated disc brake based on 3D thermo-mechanical coupling model,” J. Mech. Sci. Technol., vol. 24, no. 1, pp. 81-84, 2010.

[7] A. Belhocine and M. Bouchetara, "Investigation of temperature and thermal stress in ventilated disc brake based on 3D thermomechanical coupling model,” Ain Shams Eng. J., vol. 4, no. 3, pp. 475-483, 2013.

[8] A. Belhocine and M. Bouchetara, "Thermal behavior of full and ventilated disc brakes of vehicles," J. Mech. Sci. Technol., vol. 26, no. 11, pp. 3643-3652, 2012.

[9] A. Belhocine and M. Bouchetara, “Thermal analysis of a solid brake disc," Appl. Therm. Eng., vol. 32, no. 1, pp. 59-67, 2012.

[10] A. Belhocine and M. Bouchetara, "Thermomechanical modelling of dry contacts in automotive disc brake,” Int. J. Therm. Sci., vol. 60, pp. 161-170, 2012. 